\title{
DESENVOLVIMENTO SUSTENTÁVEL: UMA ANÁLISE DA PERSPECTIVA DE GARANTIA PARA GERAÇÕES FUTURAS
}

\author{
Jamila Wisóski Moysés Etchezar ${ }^{92}$ \\ Bruna Chechi Biorchi ${ }^{93}$
}

Recebido em: 08/07/2018

Aprovado em: 19/10/2018

\begin{abstract}
RESUMO
O presente trabalho busca analisar o desenvolvimento sustentável de forma sucinta, com ênfase em conceitos introdutórios e a união do desenvolvimento com a sustentabilidade. Inclusive, busca sintetizar o desenvolvimento sustentável não apenas como uma matéria ambiental, mas também demonstrar a união com outras áreas. Ressalta-se que o desenvolvimento econômico dos países, necessariamente associado à preservação e à sustentabilidade da utilização dos recursos naturais, deverá buscar assegurar a elevação na qualidade de vida dos seres humanos, que dependem da disponibilidade dos recursos ambientais para garantir a conservação da própria vida no planeta. Diante deste contexto, o trabalho objetiva fazer uma relação com as gerações futuras, levando em consideração os princípios e direitos fundamentais.

Palavras-chaves: Desenvolvimento. Sustentabilidade. Desenvolvimento sustentável. Garantias. Princípios. Gerações futuras.
\end{abstract}

\section{INTRODUÇÃO}

\footnotetext{
92 Doutoranda em Direito Internacional Público pela Università Degli Studi di Pavia - Itália. Mestranda em Direito pela Faculdade Meridional de Passo Fundo. Mestre em Direito Ambiental pela Università Ca' Foscari de Veneza. Especialista em Direito do Trabalho, Processo do Trabalho e Previdenciário pela Universidade de Santa Cruz do Sul.

93 Mestranda em Direito pela Faculdade Meridional/RS MED. Pós-graduada em Direito Previdenciário pela Universidade de Caxias do Sul em convênio com a Escola da Magistratura Federal do Rio Grande do Sul ESMAFE/RS. Advogada.
} 
O desenvolvimento sustentável é um assunto que vem sido muito discutido a nível mundial, pois além de coincidir com muitas áreas, especialmente econômica, social, cultural e política, ainda se comunica com os direitos fundamentais.

Este assunto foi tema de diversas conferências internacionais ao longo dos anos. Ainda, incansavelmente, busca fazer com que estes tratados internacionais se cumpram, buscando conscientizar e discutir tratativas que venham a programar a implementação do "pensamento verde" dentro das nações.

Assim, a presente pesquisa, irá esclarecer de forma sintetizada os conceitos de desenvolvimento em suas diferentes formas. Bem como, irá de maneira mais específica conceituar pela visão dos autores que circundaram a pesquisa, o conceito de sustentabilidade.

Todavia, buscará unir os dois conceitos, desenvolvimento e sustentabilidade, para que assim se compreenda o que consiste o desenvolvimento sustentável na sua concepção mais humanística.

Posteriormente, buscará de forma breve fazer uma pequena linha do tempo para que se possa dispor marcos importantes para o desenvolvimento sustentável. Explicará de uma maneira breve o que cada um consiste e buscará fazer compreender da importância histórica.

Discorrerá sobre a garantia da sustentabilidade e a importância do desenvolvimento sustentável, para esta geração e para as futuras, evidenciando a previsão brasileira, principalmente a constante na Constituição Federal de 1988 e decorrente de conferências internacionais.

Por fim, buscará fazer um paralelo entre o direito ao meio ambiente sustentável, o desenvolvimento sustentável e a relação intrínseca entre estes e os direitos fundamentais.

\section{BREVES CONSIDERAÇÕES SOBRE DESENVOLVIMENTO SUSTENTÁVEL}

O desenvolvimento sustentável é um dos maiores desafios do século XXI, pois se contrapõe ao crescimento das grandes cidades e está atrelado aos fatores econômicos e sociais. Nesse cenário existem recursos renováveis e não renováveis, mas jamais inesgotáveis, pois o uso indevido poderá extinguir sua disponibilidade na natureza.

Nessa mesma linha de raciocínio analisando o significado da palavra “desenvolvimento" é possível compreender a grandiosidade e a complexidade da ideia trazida pelo termo: "ato ou efeito de (se) desenvolver", "passagem de um estado a outro, de tal modo que o seguinte é sempre mais perfeito do que o anterior; progresso, evolução", "aumento das 
capacidades físicas ou intelectuais; crescimento", "aumento por meio de reprodução; propagação", "(estudo, investigação) tratamento em profundidade da questão proposta como tema principal, abordagem detalhada", "exposição lógica de ideias, oralmente ou por escrito; elaboração", "estado do país que apresenta um alto nível de produtividade e um nível de vida elevado; avanço tecnológico. ${ }^{94}$.

Veja-se quando se pronuncia a palavra "desenvolvimento", a ideia que de imediato se relaciona é de evolução, crescimento. Um dos grandes desafios desse século, enfrentados pelos meios científicos e tecnológicos, é a defesa da vida, envolvendo cuidado e proteção com tudo que se refere ao ser vivo, dentro de uma perspectiva planetária.

Dessa forma, entende-se como desenvolvimento sustentável a capacidade que o ser humano tem de utilizar dos recursos provenientes da natureza sem comprometer sua disponibilidade, de modo a promover a conservação desses recursos naturais para gerações futuras.

No tocante ao amplo conceito de desenvolvimento, sintetiza Zambam (2012, p.136):

Ocorre uma mudança de ordem epistemológica, relacionada com outras concepções político-metodológicas de desenvolvimento, elegendo, em primeiro plano, as prioridades relacionadas com as necessidades humanas, sociais, ambientais e culturais e, também, com os demais aspectos que envolvem esse panorama, Esse novo paradigma não restringe a evolução da sociedade às determinações, necessidades e demandas do progresso econômico, mas submete toda essa rede de relações que constitui a estruturação e a organização da sociedade a uma avaliação, considerando, prioritariamente, o critério da sustentabilidade.

A qualidade sustentável é um ideal de desenvolvimento, sendo que no seu interior está um conjunto de princípios e convicções que orientam as ações pessoais, as políticas públicas, as iniciativas empresarias ou de outras instituições, com menor ou maior abrangência e condições de influência. (ZAMBAM, 2012, p. 206)

Destarte que, ao estudar o desenvolvimento sustentável é de extrema importância a compreensão do contexto de sustentabilidade em específico. Nesse sentido, Bosselmann (2008, p. 25) nos ensina que a sustentabilidade se divide em duas definições, sendo elas simples e ao mesmo tempo complexa, veja-se:

\footnotetext{
Sustentabilidade é ao mesmo tempo simples e complexa. Semelhante à ideia de justiça. A maioria de nós sabe intuitivamente quando alguma coisa não é justa. Da mesma forma, a maioria de nós tem plena consciência das coisas insustentáveis. [...] $\mathrm{Na}$ sua forma mais elementar, a sustentabilidade reflete a pura necessidade o ar que respiramos, a água que bebemos, os solos que fornecem o nosso alimento são essenciais para a nossa sobrevivência. [...] Porém, a sustentabilidade também é complexa, novamente, como é justiça. É difícil afirmar categoricamente o que é
}

\footnotetext{
${ }^{94}$ Dicionário infopédia da Língua Portuguesa.
} 
justiça. Não existe uma definição uniformemente aceita. Justiça não pode ser definida sem uma reflexão mais aprofundada sobre seus critérios de orientação, valores e princípios. Tal reflexão é subjetiva por natureza aberta ao debate. A mesma ideia é verdadeira para a sustentabilidade, pois não pode ser definida sem uma maior reflexão sobre valores e princípios. Assim qualquer discurso sobre a sustentabilidade é essencialmente um discurso ético.

Portanto a definição de sustentabilidade, é uma mescla entre a preservação de meios necessários a sobrevivência, ou seja, dos recursos naturais, mas também, o sobrepesamento de valores e princípios.

Ainda, Bolssemann expõe uma analogia de a justiça à sustentabilidade, da qual podemos extrair o entendimento que em termos de justiça é sabido o que é justo ou não. $\mathrm{O}$ mesmo ocorre com a sustentabilidade, internamente é possível distinguir o que é ou não sustentável. (2008, p. 25)

A Sustentabilidade é princípio jurídico, o qual já aparece em documentos internacionais e orienta outros princípios e regras, como é o caso do Desenvolvimento Sustentável. No entanto, a sua execução depende de ações transversais que demandem, mais e mais, essa compreensão das relações humanas e não humanas. Precisa-se, sim, de uma governança para a Sustentabilidade, a qual já define outros contornos de atuação do Direito Ambiental Internacional.

Diante disso, o valor moral substantivo do adjetivo "sustentabilidade" afirma-se com base na concepção universalista, pois, especificamente em relação às futuras gerações, não é possível saber, por exemplo, quais necessidades deverão ser satisfeitas, que estrutura social, responderá às suas aspirações, qual a capacidade de geração de bens e quais existirão. Assim, o critério da sustentabilidade, nessa compreensão, orienta o conjunto do comportamento humano. O desenvolvimento econômico opera, nessa nova perspectiva como um meio importante para o desenvolvimento humano sustentável. (ZAMBAM, 2012, p. 138 e 139).

Observa-se que do desenvolvimento econômico dos países, necessariamente associado à preservação e à sustentabilidade da utilização dos recursos naturais, deverá buscar assegurar a elevação na qualidade de vida dos seres humanos, que dependem da disponibilidade dos recursos ambientais para garantir a conservação da própria vida no planeta.

É consabido que, por meio de um processo educativo direcionado para as questões ambientais que serão construídos novos valores que ensejarão a transformação política necessária em nossa ordem social, pública e jurídica, que serão, por seu turno, indutoras de uma efetiva mudança nos processos de exploração dos recursos ambientais.

Diante de tais definições, é necessário que se compreenda a união da sustentabilidade com o desenvolvimento, em outras palavras, o desenvolvimento sustentável como a 
[...] possibilidade de utilização (produção e consumo) consciente e sustentável de um meio ambiente equilibrado, levando em consideração as gerações atuais e vindouras. O desenvolvimento sustentável, nesse sentido, deve perceber a proteção do ambiente como parte integrante do processo de desenvolvimento, não podendo ser considerado de forma isolada. (HAMEL; GRUBBA, 2016, p. 109)

De tal sorte, é possível perceber que o desenvolvimento sustentável não consiste apenas no meio ambiente e sua preservação, mas sim, na união dele com outras áreas, senão, vejamos:

\begin{abstract}
Trata-se de uma concepção de complexidade ambiental, que ultrapassa a complexidade da natureza e/ou recursos naturais, representando as dimensões da vida humana e natural. Essa noção de complexidade permite a percepção do ser humano como parte integrante do meio ambiente no qual está inserido, possibilitando pensar a diminuição dos riscos ambientais.

De um lado, solidificam-se avanços da legislação ambiental, contemplando a proteção do meio ambiente, no fim precípuo de preservar áreas fundamentais para evitar a degradação da natureza e suas decorrências, por vezes danosas aos seres e ao meio em que vivem. Contudo, de outro lado, expõe-se o desenvolvimento industrial, produtivo, tecnológico, econômico e social, de forma acelerada, presente cada vez mais na sociedade moderna e atual. (HAMEL; GRUBBA, 2016, p. 100-101)
\end{abstract}

Assim, o ser humano, dentro da complexidade ambiental, é parte fundamental, no contexto ambiental, pois atua possibilitando a redução dos riscos ambientais, sendo o fim precípuo do direito ambiental a proteção do meio ambiente.

Sachs (2008, p. 15-16) vai além, ele classifica o desenvolvimento sustentável com a composição de cinco pilares, que são eles:

a-Social, fundamental por motivos tanto intrínsecos quanto instrumentais, por causa
da perspectiva de disrupção social que paira de forma ameaçadora sobre muitos
lugares problemáticos do nosso planeta; b-Ambiental, com as suas duas dimensões
(os sistemas de sustentação da vida como provedores de recursos e como
"recipietes" para a disposição de resíduos); c-Territorial, relacionado à distribuição
espacial dos recursos, das populações e das atividades; d-Econômico, sendo a
viabilidade econômica a condido sine qua non para que as coisas aconteçam e-
Político, a governança democrática é um valor fundador e um instrumento
necessário para fazer as coisas acontecerem; a liberdade faz toda a diferença;

Dessa forma, é possível assimilar que há uma complexidade expressiva do desenvolvimento sustentável, e está para além de questões ambientais. É necessário o entendimento que o desenvolvimento sustentável está veemente relacionado com questões econômicas, tecnológicas, sociais, culturais, políticas dentre outras, e que a relação existente, faz com que seja estruturado e possível o crescimento das nações que lhe adotam.

Importante salientar, que o modelo de desenvolvimento sustentável impõe a existência conjunta de condições de participação e de discussões públicas que tornam possível a 
manifestação dos interesses e preocupações que compõem a complexidade das necessidades presentes e futuras. (ZAMBAM, 2012, p. 206)

Além de conceituar o desenvolvimento sustentável, é importante que se faça uma breve menção histórica da união da sustentabilidade com o desenvolvimento, em um contexto mundial.

Pode-se dizer, portanto, que o desenvolvimento sustentável possui um conteúdo político que consiste na vontade do poder público de disciplinar condutas no sentido de preservação ambiental, utilizando as normas ambientais como ferramentas para sua efetivação.

Assim, a primeira menção surgiu em 1970, onde a união de "sustentabilidade" e "desenvolvimento" foi vista com bons olhos e aderidas nos campos políticos. Contudo, deveria andar de mãos dadas com o setor econômico para que fosse bem aceito. (BOLSSEMANN, 2008, p. 47)

Importante, mencionar está ideia inicial de sustentabilidade, que considerava a sua expressão semelhantes a outras consideradas fundamentais à manutenção do convívio sadio entre as pessoas como Liberdade, Igualdade, Fraternidade e Justiça no seu sentido mais amplo.

Destaca-se, ainda que o termo "sustentabilidade" não tinha sido usado a nível mundial, sendo a primeira vez utilizada em 1970 e regulamentada em 1972 com a Declaração de Estocolmo, veja-se:

\footnotetext{
O termo sustentabilidade não tinha sido usado quando o direito internacional deu seus primeiros passos para integra o meio ambiente e o desenvolvimento. $\mathrm{O}$ princípio 13 da Declaração de Estocolmo de 1972 instou os Estados a adotarem "uma abordagem integrada e coordenada para o seu desenvolvimento, como o planejamento para garantir que seu desenvolvimento é compatível com a necessidade de proteger e melhorar o ambiente humano". Fundamentalmente, a essência da sustentabilidade também está sendo referida.
}

Nesse mesmo sentido, ao se buscar a proximidade de uma contextualização de desenvolvimento sustentável é necessário que se mencione em termos de desenvolvimento, a Comissão Mundial sobre o Meio Ambiente e Desenvolvimento (CMMAD), instituída pela Organização das Nações Unidas (ONU) em 1984, consolidou uma declaração que dispunha sobre a proteção ambiental e o desenvolvimento sustentável, que foi denominado de Relatório de Brundtland. (HAMEL; GRUBBA, 2016, p. 100-101) 
O Relatório de Brundtland previu que os seres humanos enquanto humanidade deveriam preservar os recursos naturais, para que assim tornasse possível a integralização do conceito de desenvolvimento sustentável. (HAMEL; GRUBBA, 2016, p. 100-101)

Assim, tendo em vista do que ficou estabelecido pela Comissão Mundial sobre o Meio Ambiente e Desenvolvimento, em decorrência dos novos conteúdos definitórios fornecidos pelo Relatório Bruntland, o desenvolvimento sustentável é concebido como “o desenvolvimento que satisfaz as necessidades presentes, sem comprometer a capacidade das gerações futuras de suprir suas próprias necessidades".

Destaca o referido relatório a necessidade de o desenvolvimento dos países ocorrerem em três níveis distintos: o desenvolvimento econômico, a preservação dos recursos ambientais (proteção ambiental) e a promoção da equidade social.

O Relatório de Brundtland se concentraram sobre a necessidade de reavaliar os princípios expressos em Estocolmo e de considerar o desenvolvimento sustentável como um ponto de referência essencial e irrenunciável na nova aproximação com a temática ambiental.

Por fim, o relatório determina que o principal objetido do desenvolvimento é proporcionar às sociedades a satisfação de suas necessidades básicas (alimentação, vestuário, emprego, entre outras), garantindo um bom nível de vida e de consumo para as gerações presente e futuras (melhoria da qualidade de vida da população).

Ainda de acordo com o relatório, o desenvolvimento sustentável advém de um processo de transformação no qual a exploração dos recursos, a direção de investimentos, a orientação do desenvolvimento tecnológico e a mudança institucional se harmonizam com o objetivo de atender as aspirações humanas em todos os níveis.

Ainda, em 1992 na Declaração do Rio, e a Agenda 21, foi proclamado o desenvolvimento sustentável como um direito humano. Que demonstrava a ligação entre a proteção ambiental e os direitos fundamentais. $\mathrm{O}$ anseio entre o desenvolvimento econômico e ao meio ambiente, fez com que a maioria dos movimentos sociais e também ambientais se unisse em prol da luta pelos direitos humanos. (GRUBBA; NISTLER, 2016 p. 130)

A Conferência do Rio de Janeiro de 1992 foi conclusa com a redação de três importantes documentos: A Declaração do Rio sobre o ambiente e sobre o desenvolvimento, a Agenda 21 e a Declaração dos princípios para a conservação e o desenvolvimento sustentável das florestas.

Toda essa atenção internacional, a ponto de tornar a questão da proteção ambiental uma das prioridades políticas dos governos, foi devido à degradação sistemática do meio ambiente, provocada direta ou indiretamente pelas ações do homem, as mudanças climáticas 
geradas por elas e as repecursões dramáticas observadas sobre as diversas populações do planeta.

No relatório do RIO + 20, é possível perceber que o objetivo principal foi

[...] garantir um compromisso renovado em nome do desenvolvimento sustentável, avaliando o progresso obtido até o presente e as lacunas remanescentes na implementação dos resultados das maiores cúpulas de desenvolvimento sustentável, abordando desafios novos e emergentes. O foco da Conferência incluirá os seguintes temas a serem discutidos e aperfeiçoados durante o processo preparatório: economia verde no contexto do desenvolvimento sustentável e erradicação da pobreza, e o arcabouço institucional para o desenvolvimento sustentável ${ }^{95}$.

Além disso, será tratado do quadro institucional relativo ao desenvolvimento sustentável, referindo-se ao sistema de governança global para o desenvolvimento sustentável, incluindo as instituições encarregadas de desenvolver, monitorar e implementar políticas de desenvolvimento sustentável através de seus três pilares: social, ambiental e econômico, com ênfase aos dois primeiros.

Substancialmente, devemos considerar como elementos fundamentais constitutívos do desenvolvimento sustentável os quatro seguintes princípios:

O princípio do uso adequado e sustentável dos recursos naturais: representado pelo uso racional e prudente das reservas naturais; - $\mathrm{O}$ princípio da equidade intergeneracional: tido como uma norma programática que impõe aos Estados considerar, na aplicação das próprias politicas, as exigências e as necessidades não somente da geração presente mas, igualmente, das futuras. Isto significa colocar um limite ao uso indiscriminado e excessivo das reservas naturais de modo a evitar a sua escassez com a finalidade de sua utilização pelas gerações futuras; - O princípio da equidade intrageneracional: todo o País nas aplicações de suas próprias políticas de desenvolvimento deve responder não somente pelas exigências de seu povo mas, também, pelas dos outros países; - Integração entre as políticas de desenvolvimento e as da tutela ambiental: trata-se de enfrentar os problemas relativos ao ambiente através da adoção de uma aproximação global e equilibrada integrando as exigências econômicas de desenvolvimento às ambientais. ${ }^{96}$

Contudo, um dos maiores problemas encontrados quando se fala em desenvolvimento sustentável, é que os "recursos naturais do Planeta são finitos e os impactos da sua utilização desenfreada são perigosos. A continuidade desse modelo de produção, extração e consumo deve ser questionada quanto à sua viabilidade a curto, médio e longo prazo". (HAMMEL; GRUBBA, 2016, p. 106)

Nesse sentido, é dever do Estado garantir ações efetivas que visem não apenas a incentivar às empresas a utilizar de forma sustentável os recursos naturais, mas, sobretudo, atuar de forma incisiva a fazer cumprir as leis de proteção ambiental, pois:

\footnotetext{
${ }^{95}$ Relatório RIO + 20.

96 BASILE, Gianluca. Compendio di Diritto dell'Ambiente, Aggiornato al D.Lgs. 29 giugno 2010, n. 128, $5^{\text {a }}$ edizione, Napoli, Italia. Editora Esselibri-Simone, 2010, p. 21.
} 
[...] a razão suprema de ser do Estado reside justamente no respeito, proteção e promoção da dignidade dos seus cidadãos, individual ou coletivamente considerados, devendo, portanto, tal objetivo ser continuamente perseguido e concretizado pelo Poder Público e pela própria sociedade, constitui já um dos lugares-comuns e postulados do Estado Constitucional (democrático e socioambiental de Direito) contemporâneo. Nesta perspectiva, os deveres de proteção no âmbito do Estado Constitucional estão alicercados no compromisso (político e jurídico-constitucional) assumido pelos entes estatais, por meio do pacto constitucional, no sentido de tutelar e garantir nada menos do que uma vida digna $e$ saudável aos indivíduos e grupos sociais, o que passa pela tarefa de promover a realização dos seus direitos fundamentais, retirando possíveis óbices colocados a sua efetivação. De acordo com tal premissa, a implantação das liberdades e garantias fundamentais (direito à vida, livre desenvolvimento da personalidade, etc.) pressupõe uma ação positiva (e não apenas negativa) dos poderes públicos, no sentido de remover os "obstáculos" de ordem econômica, social e cultural que impeçam o pleno desenvolvimento da pessoa humana. Nesse sentido, uma vez que a proteção do ambiente e alçada ao status constitucional de direito fundamental (além de tarefa e dever do Estado e da sociedade) e o desfrute da qualidade ambiental passa a ser identificado como elemento indispensável ao pleno desenvolvimento da pessoa humana, qualquer "óbice" que interfira na concretização do direito em questão deve ser afastado pelo Estado, seja tal conduta (ou omissão) obra de particulares, seja ela oriunda do próprio Poder Público. (Sarlet e Fensterseifer, 2011, p. 16-17)

Nesse cenário, considerando que a razão de ser do Estado também se encontra no âmbito socioambiental, com reconhecimento como um direito fundamental da pessoa humana, é que se espera um crescimento de ações de fiscalização empresarial, não só isso, como por exemplo, incentivos fiscais (ou não), às empresas que venham a atuar de maneira sustentável.

Nem sempre o problema se encontra na escassez natural, mas em muitos casos o problema se encontra no seu mau uso, decorrente de ações humanas, como lembra Hammel e Grubba:

A situação problemática da água, na verdade, não reside na sua escassez, e sim nas ações e práticas do homem com os recursos existentes, como poluição, apropriação da água por empresas privadas com finalidades econômicas e falta de serviços adequados de abastecimento e saneamento. (2016, p. 106)

Nesse viés, o desenvolvimento sustentável pode ser caracterizado como um processo de mudanças, que pode orientar as práticas para a economia para determinada nação com o fim de prover melhores condições de vida para a população. Contudo, estas práticas econômicas devem respeitar os recursos naturais, utilizando-se apenas do necessário para que seja mantido/preservada o bem-estar da população. (GRUBBA; NISTLER, 2016 p. 130)

Disso pode-se entender que o desenvolvimento sustentável nem sempre se encontra na falta de recursos naturais, mas na falta de ações sociais do manejo desses recursos. 


\title{
3 UMA PERSPECTIVA HUMANA PARA GARANTIA DE GERAÇÕES FUTURAS
}

Na sociedade atual, uma das grandes preocupações é a garantia do bem-estar, e os direitos de viver bem da população. Conforme demonstrado anteriormente, o desenvolvimento sustentável é de extrema importância, pois abrange contextos econômicos, tecnológicos, sociais, culturais e políticos.

Assim, se faz necessário, analisar em um cenário atual e futuro, se no mundo atual, há possibilidade de garantias sustentáveis para a gerações futuras. Ao fazer uma análise constitucionalista se falar de Brasil, a Constituição Federal de 1988 veio reconhecer os direitos ambientais, prefixando a responsabilidade dos entes estatais na preservação do meio ambiente, para a geração atual e também para as vindouras, como pode ser veemente observado no artigo $225^{97}$, conforme termos que seguem:

\begin{abstract}
Artigo 225. Todos têm direito ao meio ambiente ecologicamente equilibrado, bem de uso comum do povo e essencial à sadia qualidade de vida, impondo-se ao Poder Público e à coletividade o dever de defendê-lo e preservá- lo para as presentes e futuras gerações. $\S 1^{\circ}$ Para assegurar a efetividade desse direito, incumbe ao Poder Público: I - preservar e restaurar os processos ecológicos essenciais e prover o manejo ecológico das espécies e ecossistemas; II - preservar a diversidade e a integridade do patrimônio genético do País e fiscalizar as entidades dedicadas à pesquisa e manipulação de material genético; III - definir, em todas as unidades da Federação, espaços territoriais e seus componentes a serem especialmente protegidos, sendo a alteração e a supressão permitidas somente através de lei, vedada qualquer utilização que comprometa a integridade dos atributos que justifiquem sua proteção; IV - exigir, na forma da lei, para instalação de obra ou atividade potencialmente causadora de significativa degradação do meio ambiente, estudo prévio de impacto ambiental, a que se dará publicidade; V - controlar a produção, a comercialização e o emprego de técnicas, métodos e substâncias que comportem risco para a vida, a qualidade de vida e o meio ambiente; VI - promover a educação ambiental em todos os níveis de ensino e a conscientização pública para a preservação do meio ambiente; VII - proteger a fauna e a flora, vedadas, na forma da lei, as práticas que coloquem em risco sua função ecológica, provoquem a extinção de espécies ou submetam os animais a crueldade.
\end{abstract}

O conceito de desenvolvimento sustentável pode ser vislumbrado constitucionalmente através da análise do art. 3, II, que prevê o desenvolvimento nacional como imperativo a ser cumprido pelo poder público, do art. 170, VI, que trata da defesa do meio ambiente nas atividades econômicas e do art. 225 que determina as modalidades jurídicas que visam prevenir os danos lesivos ao meio ambiente, garantindo ao ser humano viver num meio ambiente equilibrado.

${ }^{97}$ BRASIL. Constituição Federal. 
Diante disso, uma dos objetivos principais do Estado brasileiro é a garantia do desenvolvimento nacional, nos termos do art. 3, II, da Constituição Federal Brasileira ${ }^{98}$, conferindo ao Estado a obrigação imediata de elaborar políticas públicas visando promover o bem da nação.

A Constituição Federal de 1988, em seu artigo 225, assegurou como Direito Fundamental que o Meio Ambiente deve ser preservado por todos e para todos. Nessa primeira parte, verifica-se a congruência do texto constitucional ao tutelar a importância não apenas do Direito à Vida, mas, também, à Existência.

No entanto, ao final do artigo 225 da Constituição Federal, a imposição de cumprimento deste dever não se coaduna com uma Soberania compartilhada ou responsável, pois essa tarefa pertence ao Poder Público e à Coletividade, ou seja, apenas o Cidadão brasileiro tem essa incumbência, revelando uma perspectiva de autossuficiência na gestão de um Bem Comum.

Note-se, que o artigo 225 da Constituição Federal, se reporta a uma coletividade de pessoas indefinidas, o que mostra seu caráter transindividual, em que não se determinam, rigorosamente, os titulares de direito. O meio ambiente é bem de uso comum do povo, podendo ser usufruído por toda e qualquer pessoa dentro dos limites previstos no próprio texto constitucional, sendo considerado, também, de natureza difusa essencial à qualidade de vida.

A estes direitos, tidos como transindividuais e difusos, se conecta o princípio da dignidade humana e, entre tantos outros, se destaca o desenvolvimento econômico e a proteção ambiental. Não se tira a credibilidade ou a importância dos fundamentos de outros princípios e regras constitucionalizadas.

Além disso, é preciso evidenciar a relação intrínseca entre o desenvolvimento sustentável e o meio ambiente, na medida em que ambos são considerados atores de fundamental importância no desenvolvimento da sociedade e referem-se a interesses difusos.

Entende-se, que a adoção de políticas públicas dotadas de responsabilidade ambiental, pautada sob o princípio do desenvolvimento sustentável a partir da utilização maciça e crescente de recursos ambientais renováveis e autossustentáveis condiz muito com todo o aparato legal que dispomos hoje para garantir um meio ambiente ecologicamente equilibrado a todos.

\footnotetext{
${ }^{98}$ Art. $3^{\text {o }}$ Constituem objetivos fundamentais da República Federativa do Brasil: (...) II- garantir o desenvolvimento nacional;
} 
Basta analisar a recente Constituição Federal em comparação às previsões anteriores resta cristalino a evolução obtida, que segundo Sarlet e Fensterseifer:

\begin{abstract}
Ajustada a evolução no âmbito do direito constitucional comparado registrada na última quadra do Século XX, especialmente por força da influência do ordenamento internacional (onde se consolidou todo um conjunto de convenções e declarações em matéria de proteção ambiental), a Constituição da República Federativa do Brasil, de 05 de outubro de 1988 (doravante CF88), consagrou, em capítulo próprio (art. 225), o direito ao ambiente ecologicamente equilibrado como direito (e dever!) fundamental da pessoa humana e estabeleceu um conjunto de princípios e regras em matéria de tutela ambiental, reconhecendo o caráter vital da qualidade (e segurança) ambiental para o desenvolvimento humano em níveis compatíveis com a sua dignidade, no sentido da garantia e promoção de um completo bemestar existencial. (2011, p. 12-13)
\end{abstract}

Sendo assim, é possível considerar que o conceito de uma sociedade sustentável está intimamente ligada à garantia fundamental da dignidade da pessoa humana. Porquanto, trata de proteger o presente para garantir um futuro melhor, com maiores e melhores condições de vida.

Neste mesmo sentido, é possível relacionar o que Sachs (2008, p. 15) ensina sobre o conceito de desenvolvimento sustentável, que "ela é baseada no duplo imperativo ético de solidariedade sincrônica com a geração atual e de solidariedade diacrônica com as gerações futuras."

A existência de um ecossistema equilibrado, considerando toda a forma de vida, torna possível a garantia de direitos básicos, prerrogativas estas inerentes ao próprio ser, não sendo possível nada e ninguém retirá-lo. O direito a um meio ambiente sustentável faz parte de uma série de direitos fundamentais ao homem.

É em cima desta ideia que Del'Olmo refere que um ambiente ecologicamente equilibrado está intimamente ligado ao direito à vida o qual é a sustentação para os demais direitos, eis que é fundamental para que a dignidade seja garantida, que haja uma vida saudável com qualidade e por este motivo que um ecossistema equilibrado faz parte de um direito fundamental do homem. (2009, p. 226)

Neste sentido, Grubba (2017, p. 161) ensina:

Assim, se for certo que se devem resguardar as mesmas possibilidades para as gerações futuras, também parece certo que deve partilhas essas mesmas possibilidades com as pessoas da época atual, impedindo o alargamento das injustiças de acesso à melhoria da qualidade de vida, em razão de diferenças de raça, etnia, nascimento, gênero, ou questões econômicas. Garantir que o mundo seja um lugar de vida saudável e gratificante, atual e futuramente parece ser o grande desafio do desenvolvimento. 
Pensar a ideia de sustentabilidade é pensá-la aliada a contextos dos debates atuais, conectados a projetos mundiais, continentais e nacionais de preservação do ambiente, da vida humana e da vida do planeta. Imperioso, ressaltar que para atingir uma vida digna é necessária a satisfação de valores fundamentais capazes de promover as necessidades básicas dos indivíduos, proporcionando-lhes bens mínimos para garantia da dignidade.

Assim, para que os indivíduos possam desfrutar de sadia qualidade de vida, trata-se de incorporar a dignidade humana como um dos fundamentos mais importantes do Estado Democrático de Direitos.

\section{CONSIDERAÇÕES FINAIS}

Em um primeiro momento, se buscou atentar para o conceito de desenvolvimento, sustentabilidade e a união dos dois conceitos, formando assim o desenvolvimento sustentável. Historicamente, objetivou demonstrar a importância dos marcos de proteção sustentável para que se entenda a disposição a nível mundial, e ainda se compreenda o porquê da preocupação com a sustentabilidade do meio ambiente.

Em um segundo momento, se tornou necessário atentar para o fato de que o desenvolvimento e a sustentabilidade são o adequado caminho para o progresso da humanidade. Entretanto, para que esse objetivo seja alcançado metas devem ser traçadas no âmbito social, ambiental, econômico, com isso se busca um equilíbrio que resulte em desenvolvimento.

A pesquisa buscou demonstrar que o desenvolvimento vai muito além de crescimento econômico, abrange esse não só no patamar material, mas também nas vias pessoais que vão de encontro com os princípios fundamentais: dignidade da pessoa humana, isonomia, direitos econômicos, sociais e culturais.

Uma sociedade desenvolvida implica em um desenvolvimento da população, ou seja, para o desenvolvimento da população é necessário que se atente para a igualdade, equidade e a solidariedade, para só posteriormente possamos falar em um contexto econômico.

Ademais, ainda, cumpre o destaque que o desenvolvimento, distinto do crescimento econômico, é uma espécie de meta para alcançar uma vida melhor, de certa forma uma vida mais completa e se pode inclusive chamar de uma vida feliz, para todos. 
A união do desenvolvimento sustentável com o crescimento econômico pode abrir os olhos da geração atual fazendo com que preserve a sua própria geração, e inclusive também se reavinha para com as gerações futuras, formando assim uma dimensão solidaria.

Neste sentido, se faz necessário o destaque de pontos importantes no que tange ao desenvolvimento sustentável, os quais devem ser observados, posto que são necessários para colaboração do desenvolvimento em âmbitos: social, ambiental, territorial, econômico e político. Destarte que, estes pontos são de extrema importância para evite crises futuras.

Mesmo cumprindo com todos os pontos propostos, ainda assim não é possível "garantir” as gerações futuras. Contudo, é possível que seja diminuído os danos para que as gerações vindouras, possuam uma qualidade de vida digna e humanitária. Ainda, se faz necessário que as medidas se proponham a fazer seja feita com rigor, pois, caso não seja cumprida, pode influir no futuro.

\section{REFERÊNCIAS}

BASILE, Gianluca. Compendio di Diritto dell'Ambiente, Aggiornato al D.Lgs. 29 giugno 2010, n. 128, 5 edizione, Napoli, Italia. Editora Esselibri-Simone, 2010, p. 21.

BOLSSELMANN. Klaus. O principio da Sustentabilidade. São Paulo: Editora Revista dos Tribunais: 2015.

BRASIL. Relatório RIO + 20. Disponível em: http://www.rio20.gov.br. Acesso em junho/2018.

GRUBBA. Leilane Serratine. Direitos Humanos e Desenvolvimento Humano. $1^{\text {a }}$ Ed. Curitiba: Editora Prismas, 2017.

GRUBBA. Leilane Serratine. NISTLER. Regiane. Desenvolvimento Sustentável e a Efetivação dos Direitos Humanos. In Revista jurídica Furb. v.20. n. 43 2016.. Disponível em: http://proxy.furb.br/ojs/index.php/juridica/article/view/5909.

HAMEL, Eduardo Henrique; GRUBBA, Leilane Serratine. Desafios do desenvolvimento sustentável e os recursos naturais hídricos. In Revista Brasileira de Direito (IMED). v. 12. n. 1. $2016 . \quad$ Disponível em: https://seer.imed.edu.br/index.php/revistadedireito/article/view/1111/841. 
SACHS, Ignacy. Desenvolvimento: includente, sustentável e sustentado. Rio de Janeiro: Garamond, 2008.

SARLET, Ingo Wolfgang; FENSTERSEIFER, Tiago. O Papel do Poder Judiciário Brasileiro na Tutela e Efectivação dos Direitos (e Deveres) Sócio Ambientais. In Direito Público Sem Fronteiras. Lisboa, Portugal: Instituto de Ciências Jurídico-Político, 2011.

ZAMBAM, Neuro. Amartya Sen: liberdade, justiça e desenvolvimento sustentável. Passo Fundo: Imed, 2012.

DEL'OLMO, Elisa Ceriolli. Meio Ambiente Ecologicamente Equilibrado: direito e dever do cidadão. In: SANTOS, André Leonardo Copetti; DEL'OMO, Florisbal de Souza (Orgs.) Diálogo e Entendimento: direito e multiculturalismo e cidadania e novas formas de solução de conflitos. Rio de Janeiro: Forense, 2009.

\title{
SUSTAINABLE DEVELOPMENT: AN ANALYSIS OF THE GUARANTEE PERSPECTIVE FOR FUTURE GENERATIONS
}

\begin{abstract}
The present work seeks to analyze sustainable development in a succinct manner, with emphasis on introductory concepts and the development Union with sustainability. It also seeks to synthesize sustainable development not only as an environmental matter, but to demonstrate the union with other areas. It is emphasized that the economic development of the countries, necessarily associated with the preservation and sustainability of the use of natural resources, should seek to ensure the rise in the quality of life of human beings, who depend on the Availability of environmental resources to ensure the preservation of life on the planet. Given this context, the work aims to make a relationship with future generations, taking into account fundamental principles and rights.
\end{abstract}

Keywords: Development. Sustainability. Sustainable development. Guarantees. Principles. Future generations. 